\title{
Relationship of Physical Parameters in Pb-Contaminated by Stabilization/Solidification Method
}

\author{
Saiful Azhar Ahmad Tajudin ${ }^{1, a}$, Mohamad Azim Mohammad Azmi ${ }^{1}$, Shahiron Shahidan ${ }^{1}$, Mohd \\ Hazreek Zainal Abidin ${ }^{1}$ and Aziman Madun ${ }^{1}$ \\ ${ }^{1}$ Faculty of Civil and Environmental Engineering, University Tun Hussein Onn Malaysia, 86400 Parit Raja, Johor, \\ Malaysia
}

\begin{abstract}
This research was performed to investigate the relationship between compressive strength, density and water absorption of $\mathrm{Pb}$-contaminated soil treated by Ordinary Portland cement (OPC) incorporated with sugarcane bagasse (SCB) using the Stablisation/Solidification (S/S) method. The SCB and OPC varying from $5 \%$ to $15 \%$ was added to stabilize and solidify the $\mathrm{Pb}$-contaminated soil. The cylindrical samples were prepared and cured at room temperature for 28 days. Unconfined compression test, density test and water absorption test were conducted on these samples. The relationship between these variables were determined using simple statistical method by Analysis of Variance (ANOVA). Results indicate that there is a strong relationship between compressive strength and density with a regression coefficient of $77.4 \%$. There is also a significant relationship between density and water absorption of approximately $70.7 \%$. In addition, compressive strength and water absorption produced a strong relationship which is $73.6 \%$ of variability in strength development. In a nutshell, the strong relationship between these three variables represent the actual physical characteristics in $\mathrm{S} / \mathrm{S}$ application.
\end{abstract}

\section{Introduction}

The stabilization/solidification (S/S) method has been widely accepted and has become an important part of environment technology worldwide. Stabilization refers to techniques which reduce the hazard potential of waste by converting the contaminants into their least soluble, mobile or toxic form [1]. The physical nature characteristics of waste are not necessarily changed by stabilization. On the other hand, solidification refers to a technique that encapsulates waste in a monolithic solid of high structural integrity. Generally, $\mathrm{S} / \mathrm{S}$ method involves mixing of waste with binder to improve the physical and chemical properties of soil. Typically, there are many binders which have been developed for S/S method and the most commonly used is Portland cement [2]. The S/S method with cement is relatively common due to universal availability, desirable hydration properties and suitability for heavy metal immobilization [3-6]. This process is particularly suitable for heavy metal remediation and has been widesly applied over several decades, especially in the U.S.

\footnotetext{
${ }^{\text {a }}$ Corresponding author : saifulaz@uthm.edu.my
} 
The addition of cement to soil is mainly to modify its physical characteristics, increase strength, stiffness and durability while reducing water permeability through a chemical hardening reaction [7]. Basically, the physical characteristics involve several tests such as unconfined compression strength test (UCS), density and water absorption test. These tests are important to measure the effectiveness and efficiency of soil remediation in the S/S method. Malviya and Chaundhary [8] stated that these tests produce significant relationship during the $\mathrm{S} / \mathrm{S}$ process that affects strength development. Therefore, this study was undertaken to find out the relationship between UCS, density and water absorption of $\mathrm{S} / \mathrm{S}$ samples containing cement incorporated with sugarcane bagasse.

\section{Materials and Methods}

\subsection{Contamination of soil}

Clay soil samples were collected at a location near to the Research Center for Soft Soil (RECESS), University Tun Hussein Onn Malaysia (UTHM). The top of the soil to a depth of 3 meters was withdrawn in order to avoid taking the humus and plant sources [9]. The soil sample was oven-dried at $105 \mathrm{oC}$ for 24 hours. Dried soil was crushed into fine powders prior to storage in a polyethylene plastic bag. The initial concentration of $\mathrm{Pb}$ is $500 \mathrm{ppm}$. Treatment of the lead contaminated soil was conducted using Type II ordinary Portland cement (OPC) as the main binder and supplemented by treated and untreated sugarcane bagasse (SCB). The SCB was collected from hawkers around Parit Raja, Johor and divided into two parts: the first part was untreated and the second part was treated. The untreated SCB was raw as collected but the treated SCB was exposed under acidic conditions to eliminate the possibility of cellulose fibers and to liberate the lignin. For the treated part, the SCB was boiled with $0.1 \mathrm{MHCl}$ for approximately 45 minutes, with the residue washed free of sugars and hydrolysis products. This procedure was repeated 3 to 4 times until the filtrate was virtually colorless [10]. Both types of SCB were dried in the oven under a temperature of $105{ }^{\circ} \mathrm{C}$ for 24 hours in order to eliminate the moisture content before being grinded into a particle size of $90 \mu \mathrm{m}$.

\subsection{Production of S/S sample}

The binder (OPC with untreated and treated sugarcane bagasse) was added to the contaminated soil at binder-to-dry soil (B/Sd)(w/w\%) ratio. Table 1 summarizes the mix design of sample. The $\mathrm{S} / \mathrm{S}$ sample was then compacted into a split mould to form a sample of $38 \mathrm{~mm}$ in diameter and $76 \mathrm{~mm}$ in height. A specially designed miniature hand compacting tool was used to compact the mixture in 4 layers, 50 blows each and cured at a controlled condition for 28 days (temperature $=25 \pm 2 \mathrm{oC}$, humidity $>$ $70 \%)[11]$.

Table 1. Mix design of sample.

\begin{tabular}{lccc}
\hline Mixing Type & Sample & Percentage of Binder & $\begin{array}{c}\text { Total Weight of } \\
\text { Sample (g) }\end{array}$ \\
\hline$($ Clay $+\mathrm{Pb})+\mathrm{OPC}$ & $\mathrm{A}$ & $5 \% \mathrm{OPC}$ & 160 \\
$($ control $)$ & $\mathrm{B}$ & $10 \% \mathrm{OPC}$ & 160 \\
& $\mathrm{C}$ & $15 \% \mathrm{OPC}$ & 160 \\
\hline$($ Clay $+\mathrm{Pb})+\mathrm{OPC}+$ & $\mathrm{D}$ & $2.5 \% \mathrm{OPC} 2.5 \% \mathrm{SCB}$ & 160 \\
$\mathrm{SCB}($ untreated $)$ & $\mathrm{E}$ & $5 \% \mathrm{OPC} 5 \% \mathrm{SCB}$ & 160 \\
& $\mathrm{~F}$ & $7.5 \% \mathrm{OPC} 7.5 \% \mathrm{SCB}$ & 160 \\
\hline$(\mathrm{Clay}+\mathrm{Pb})+\mathrm{OPC}+$ & $\mathrm{G}$ & $2.5 \% \mathrm{OPC} 2.5 \% \mathrm{SCB}$ & 160 \\
$\mathrm{SCB}($ treated $)$ & $\mathrm{H}$ & $5 \% \mathrm{OPC} 5 \% \mathrm{SCB}$ & 160 \\
& $\mathrm{I}$ & $7.5 \% \mathrm{OPC} 7.5 \% \mathrm{SCB}$ & 160 \\
\hline Clay $+\mathrm{Pb}$ & $\mathrm{J}$ & - & 160 \\
\hline
\end{tabular}




\subsection{Unconfined compressive strength (UCS)}

The UCS test was carried out using the GeocompLoadTrac II system available in RECESS UTHM. Testing was conducted according to BS1377-7:1990. The samples were extruded from the moulds, levelled, measured for length and diameter, weighed and subjected to uniaxial compression test (UCT) at a constant rate of strain of $1 \%$ per minute. Before testing, the loading device was adjusted carefully to ensure the upper platen made contact with the sample. Extra care was taken to ensure that both ends of the sample were as flat as possible to minimize bedding error during the test, especially for the stiffer samples.

\subsection{Density test}

The density test is an easy test which is carried out in order to determine the tapped bulk density of samples. In this test, the bulk density is measured by calculating the volume of the soil and weight. The testing involved the measurement of height and diameter of each sample. Finally, the weight of soil is divided by the total soil volume.

\subsection{Water absorption test}

Water Absorption is one of the important tests for the $\mathrm{S} / \mathrm{S}$ method, with which infiltration into the disposed solidified matrices can be detected [12]. The water adsorption test was conducted according to ASTM C 140. Principally, the test consists of two major factors which are saturating the specimen followed by drying. The specimens will be immersed in water until a change in mass takes place during 24 hours. Then, the obtained saturated mass of soil will be weighed and dried in the oven at a temperature of $105^{\circ} \mathrm{C} \pm 5^{\circ} \mathrm{C}$. Thereafter, the water absorption by immersion will be estimated using the saturated weight minus dry weight and divided by the dry weight [13].

\subsection{Relationship analysis}

The results of UCS, density and water absorption of the sample were then analyzed using simple statistical analysis which is analysis of variants (ANOVA) to determine the relationship between the variables.

\section{Results and Discussion}

\subsection{Relationship between strength and density}

Generally, there is a linear relationship between strength and density of sample. Figure 1 presents a compressive strength against density at 28 days. The influence of strength on the density values is showed using a regression coefficient. Distribution of data shows a linear relationship between the compressive strength and density as follows.

$$
\sigma=1389.4+0.24 \alpha
$$

with $\sigma$ being the compressive strength $(\mathrm{kPa})$ and $\alpha$ is the density $\left(\mathrm{Kg} / \mathrm{m}^{3}\right)$ of the sample.

Statistical analysis showed that there was a significant relationship between two variables as Pvalue in the analysis of variance (ANOVA) indicated that $\mathrm{P}=0.006$, which is lower than 0.05 . Linear Equation (1) described that one density unit of 0.24 increased the strength by approximately 1389.4. In addition, the positive value indicates that the strength increases with the density. Apart from that, the strong regression coefficient of $77.4 \%$ shows the variability in compressive strength. 


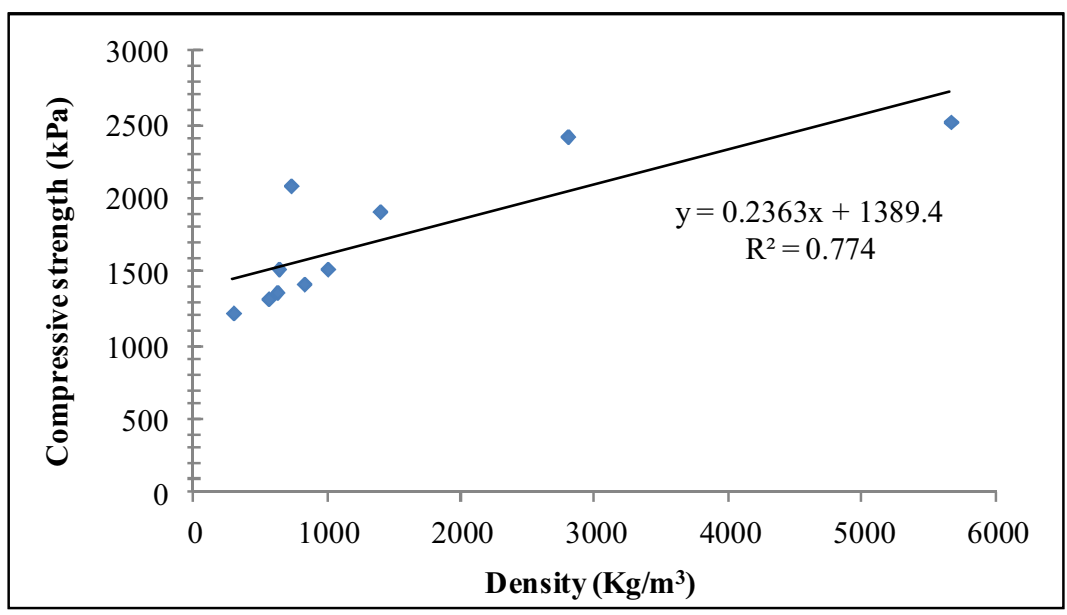

Figure 1. Relationship between compressive strength and density at 28 days.

\subsection{Relationship between strength and water absorption}

Figure 2 shows that the compressive strength of samples decreases with increasing water absorption. Through observation of the data, the linear model was used to describe the relationship between the strength and absorption of water. This linear equation expresses the relationship as follows:

$$
\sigma=4054.9-77.17 \alpha
$$

where $\sigma$ is the compressive strength $(\mathrm{kPa})$ and $\alpha$ is the water absorption $(\%)$ of the sample. Statistical analysis showed that there were significant correlations at the $95 \%$ confidence level between two variables. This is because the P-value in the analysis of variance is 0.007 , which is lower than 0.05 . However, regression analysis showed that this model explains $73.6 \%$ of variability in strength. This means that there is a strong relationship between these two variables. In addition, the linear Equation (2) indicates that one water absorption unit of 77.17 may increase the sample strength by approximately 4054.9 .

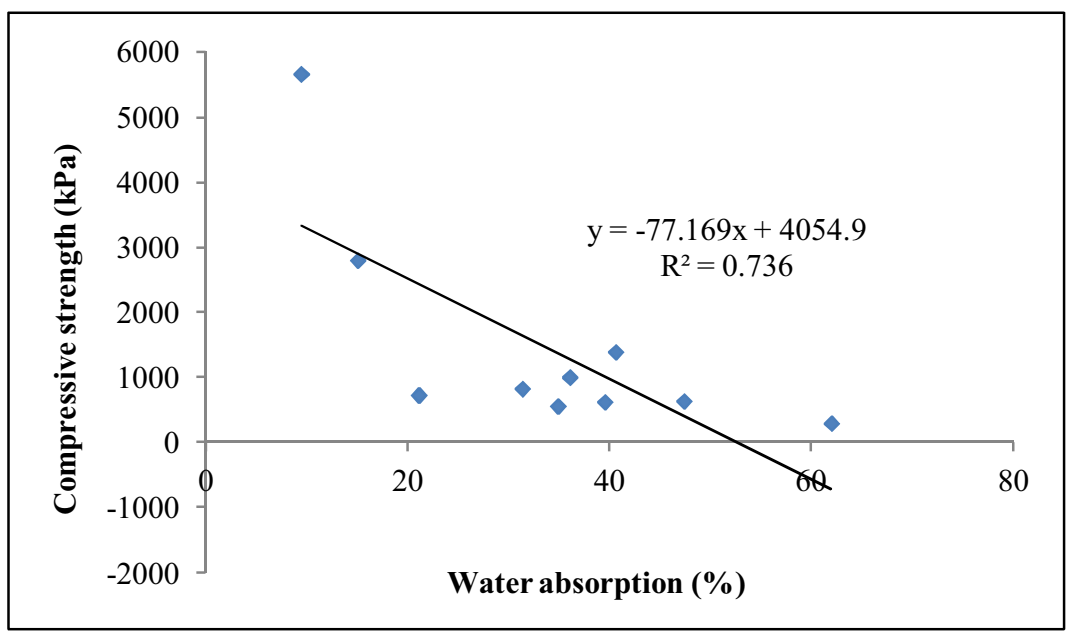

Figure 2. Relationship between compressive strength and water absorption at 28 days. 


\subsection{Relationship between density and water absorption}

In general, the low density of the material will reduce the absorption of water[14]. Therefore, based on the Figure 3, a linear relationship between density and water absorption can be obtained as follows:

$$
\rho=2583.7-25.23 \alpha
$$

with $\rho$ as the density $\left(\mathrm{Kg} / \mathrm{m}^{3}\right)$ and $\alpha$ as the water absorption (\%) of the sample.

Statistical analysis showed that there were significant correlations at the $95 \%$ confidence level between density and water absorption. It is proven by the P-value obtained in analysis of variance (ANOVA) which is 0.007 , greater than 0.05 . Additionally, analysis of regression coefficients $\left(\mathrm{R}^{2}\right)$ showed that this model can explain $70.7 \%$ of the variability in density where it indirectly describes the strong relationship between these two variables. On the other hand, the linear Equation 3 showed that one water absorption unit of 25.23 may affect the density at 2583.7.

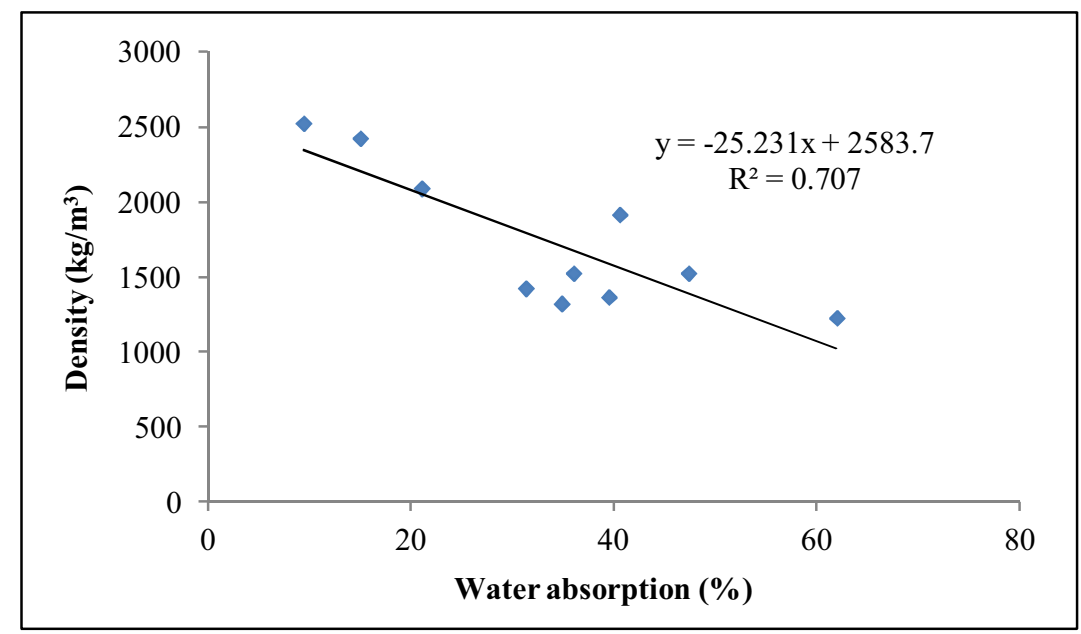

Figure 3. Relationship between density and water absorption at 28 days.

\section{Conclusions}

Analysis of variance (ANOVA) showed that there is a strong relationship between cement content and bagasse with compressive strength, density and water absorption. However, there are significant weaknesses in this relationship as the negative value of density occured as a result of high percentage of water absorption which is over $10 \%$. Similarly, the relationship between strength and water absorption is also negative due to the high percentage of water absorption. In a nutshell, this study concludes that there is significant relationship at the $95 \%$ confidence level between the strengthdensity, strength-water absorption and density-water absorption.

\section{References}

[1] M. Nur, S. Mohamed, S. Azhar, A. Tajudin, A.A. Kadir, A. Madun, M. Azim, M. Azmi and N.S. Nordin, Leachate characteristics of contaminated soil containing lead by stabilisation/ solidification technique, J. of Applied Mechanics and Materials, 774, 1443-1447, (2015).

[2] M. Azim, M. Azmi, S.A. Tajudin and A.A. Kadir, Remediation of zinc contaminated soils by stabilization / solidification technique, Int. J. of Zero Waste Generation, 1(2), 1-4, (2013). 
[3] M.J. Harbottle, A. Al-Tabbaa and C.W. Evans, A comparison of the technical sustainability of in situ stabilisation/solidification with disposal to landfill, J. Hazardous Material, 141(2), 430-440, (2007).

[4] Q.Y. Chen, M. Tyrer, C.D. Hills, X.M. Yang and P. Carey, Immobilisation of heavy metal in cement-based solidification/stabilisation: A review, Waste Management, 29(1), 390-403, (2009).

[5] R.B. Kogbara, A. Al-Tabbaa, Y. Yi and J.A. Stegemann, pH-dependent leaching behaviour and other performance properties of cement-treated mixed contaminated soil, J. Environmental Sciences, 24(9), 1630-1638, (2012).

[6] Y.J. Du, M.L. Wei, K.R. Reddy, Z.P. Liu and F. Jin, Effect of acid rain pH on leaching behavior of cement stabilized lead-contaminated soil, J. Hazardous Material, 271(2014), 131-40, (2014).

[7] A. Tarmizi, A. Karim, I.A. Rahman, A.A.A. Latiff and M.R. Taha, The effects of strength in lead contaminated residual soil solidified/ stabilized with cement, Int. J. of Civil and Environmental Engineering, 12(6), 8-12, (2012).

[8] R. Malviya and R. Chaudhary, Factors affecting hazardous waste solidification/stabilization: A review, J. Hazardous Material, 137(1), 267-276, (2006).

[9] M. Azim, S.A.A. Tajudin, A.A. Kadir, M.N.S. Mohamed, N.S. Nordin and M.S. Adnan, Leaching behavior of lead contaminated soil sample by using sugarcane bagasse in stabilization/ solidification method, J. of Applied Mechanics and Materials, 774, 1481-1485, (2015).

[10]M.A. Janusa, C.A. Champagne, J.C. Fanguy, G.E. Heard, P.L. Laine and A.A. Landry, Solidification/stabilization of lead with the aid of bagasse as an additive to Portland cement, Microchem. J., 65(3), 255-259, (2000).

[11]M. Ho, A. Tarmizi, C. Chan and I. Bakar, Leachability and strength of kaolin stabilized with cement and rubber, Int. J. of Sustainable Construction Engineering and Technology, 2(1), 89104, (2011).

[12]F.M. Khalaf and A.S. DeVenny, New tests for porosity and water absorption of fired clay bricks, J. Materials Civil Engineering, 14, 334-337, (2002).

[13]F. Wang, H. Wang and A. Al-Tabbaa, Leachability and heavy metal speciation of 17-year old stabilised/solidified contaminated site soils, J. Hazardous Materials, 278, 144-51, (2014).

[14]R. Nemes and Z. Jozsa, Strength of lightweight glass aggregate concrete, J. Material Civil Engineering, 18, 710-714, (2006). 